\title{
A concepção de educadores sobre violência doméstica e desempenho escolar
}

\author{
Violência doméstica e desempenho escolar \\ Paulo Celso Pereira \\ Lúcia Cavalcanti de Albuquerque Williams
}

\begin{abstract}
Resumo
Como parte de um estudo que caracterizou o desempenho escolar da criança vítima de violência doméstica, as respectivas professoras e as diretoras das escolas onde estudavam crianças vitimizadas foram convidadas a participar da pesquisa. O objetivo de tal participação foi identificar as concepções das educadoras sobre violência doméstica e desempenho escolar da criança vitimizada. Participaram do estudo 18 professoras e 10 diretoras que responderam, na escola, a uma entrevista semi-estruturada, versando sobre questões pertinentes ao objetivo do trabalho. Os dados obtidos revelaram que as educadoras possuem noções sobre violência doméstica e como devem proceder com as vítimas. O número de casos de crianças vitimizadas identificados na escola foi expressivo. Tal identificação deve-se tanto à observação das educadoras, como ao relato espontâneo do aluno (vítima). Mesmo com suas limitações, a escola se apresenta como um espaço de segurança para a criança vitimizada, podendo ser considerada um local de proteção para essas.
\end{abstract}

Palavras-chave: desempenho escolar; abuso infantil; escola.

\section{Educators' opinions on child victimization and school performance}

\begin{abstract}
As part of a study that characterized the school performance of victimized children, teachers and the school principals from where such children studied were invited to participate in this research. The objective of this participation was to identify educators' attitudes on domestic violence, and school performance of the victimized children. Eighteen teachers participated in the study and 10 school principals. Participants took part of a school interview, containing pertinent questions in regard to the study's objective. Results indicated that educators have some notions on child abuse, and on how they should act with the victims. The number of cases of victimized children identified in the school was expressive. This identification was related to the educator's observation, as well as to spontaneous disclosures from victimized students. In spite of its limitations, the school still presents itself as a safe place for the victimized child, which could be interpreted as a protective environment.
\end{abstract}

Keywords: academic achievement; child abuse; school.

\section{La concepción de educadores sobre violencia doméstica y rendimiento académico}

\begin{abstract}
Resumen
Haciendo parte de un estudio que caracterizó el rendimiento escolar de niños víctimas de violencia doméstica, fueron invitadas a participar las respectivas profesoras y directoras de las escuelas donde estudiaban niños que eran víctimas. El objetivo de esa participación fue identificar las concepciones de las educadoras sobre violencia doméstica y rendimiento escolar de los niños víctimas. Participaron del estudio 18 profesoras y 10 directoras que respondieron, en la escuela, a una entrevista semi estructurada tratando sobre cuestiones referentes al objetivo del trabajo. Los datos obtenidos revelaron que las educadoras poseen nociones sobre violencia doméstica y como deben proceder con las víctimas. El número de casos de niños víctimas identificados en la escuela fue expresivo. Tal identificación se debe no solo a la observación de las educadoras, sino que también al relato espontáneo de los alumnos (víctimas). A pesar de sus limitaciones, la escuela se presenta como un espacio de seguridad para los niños víctimas, pudiendo ser considerado un lugar de protección para ellos.

Palabras clave: rendimiento escolar; abuso infantil; escuela.
\end{abstract}


O desempenho escolar da criança deve ser analisado, considerando-se não apenas suas características pessoais, mas também seu ambiente familiar e seu ambiente escolar, pois tais fatores interagem entre si podendo ora facilitar, ora prejudicar o aluno, suas potencialidades e habilidades (Santos \& Graminha, 2005). No âmbito da aprendizagem, a interação desses fatores pode contribuir tanto para o sucesso como para o fracasso acadêmico. Tal compreensão é compatível com a concepção sistêmica, na qual o baixo rendimento escolar deve ser atribuído não só às características individuais, mas também ao seu contexto familiar, escolar e social (Marturano,1999; Pamplim, 2005).

Neste estudo será focado um fator de risco que pode estar presente no contexto familiar - a violência doméstica; visando conhecer as concepções dos educadores (ambiente escolar) sobre o referido fenômeno e como avaliam o rendimento escolar da criança vitimizada.

A criança que sofre violência em casa fica com o desenvolvimento prejudicado. Os efeitos negativos da violência intrafamiliar podem ser observados no funcionamento cognitivo e emocional e na vida escolar e social (Wolfe, Crooks, Lee, McIntyreSmith, \& Jaffe, 2003). O declínio no desempenho escolar da criança vitimizada é uma seqüela que vem sendo demonstrada tanto em pesquisas feitas no exterior, como no Brasil (Leiter \& Johnsen, 1997; Pereira \& Williams, 2008; Veltman \& Browen, 2001).

Considerando as sequielas da violência doméstica na vida acadêmica da criança vítima, é preciso saber o que pensam os educadores sobre tal fenômeno, pois a escola tem um papel fundamental no processo de desenvolvimento da criança (Lisboa \& Koller, 2004; Santos \& Graminha, 2005). Para Veltman e Browen (2001) a criança vitimizada pode ter apoio no contexto escolar, se esta desenvolver sentimentos de otimismo e um relacionamento seguro e positivo com adultos e com seus pares.

Ao caracterizar o desempenho escolar de crianças expostas à violência conjugal (vítimas indiretas de violência doméstica), Brancalhone, Fogo e Williams (2004) mostraram que essas, ao serem comparadas com o grupo controle (não vitimizado), não tinham diferenças estatisticamente significativas quanto ao rendimento escolar no Teste de Desempenho Escolar (Stein, 1994), Boletim Escolar e avaliação das mães. No entanto, houve uma diferença significativa entre os grupos (vitimizado versus não vitimizado), segundo a avaliação das professoras, ao preencherem a Escala de Avaliação da Performance Acadêmica (DuPaul, Rapport, \& Perriello, 1991). As professoras, possivelmente, sabiam quais eram as crianças expostas à violência conjugal, o que pode ter contaminado a avaliação, subestimando o desempenho escolar destas. Portanto, os autores alertam para a probabilidade da profecia autorealizadora (Weinstein, 2002).

O estudo de Brancalhone e cols. (2004) faz uma reflexão sobre as conseqüências da violência doméstica no desempenho escolar da criança, bem como a respeito da visão que a escola tem do aluno vítima do referido fenômeno. Assim, tanto o sucesso como o fracasso escolar podem ser explicados não apenas considerando as 
características do aluno, mas também da sua família e da escola (Lisboa \& Koller, 2004).

Segundo a revisão da literatura nacional, os estudos que abordam a questão do desempenho escolar indicam que a escola exerce um papel importante na performance do aluno, tanto para o sucesso como para o fracasso (Rosemberg, 1981; Santos, 2002). O estudo de Santos (2002) mostrou que alunos com uma história de vida marcada por situações adversas tendem a viver experiências negativas na escola. Segundo a autora, a escola, enquanto contexto social mais amplo, pode ser um fator de risco ou de proteção para a criança.

Rosemberg (1981) pesquisou a associação entre origem social e rendimento acadêmico (notas, aprovação/reprovação e evasão). Seu estudo encontrou uma forte associação entre esses fatores e destacou a influência dos aspectos intra-escolares na determinação do fracasso ou sucesso das crianças oriundas das classes populares.

Considerando que os estudos indicam que a escola pode ser um fator de risco ou de proteção para a criança e, considerando, também, que o trabalho de Brancalhone e cols. (2004) faz um alerta quanto a um possível pré-julgamento de professores em relação às crianças expostas à violência conjugal, sugerindo o risco da profecia auto-realizadora, o presente estudo pretende, além de conhecer a opinião de professores e diretores de escola a respeito do desempenho escolar da criança vitimizada, investigar, também, suas concepções sobre violência doméstica e possíveis implicações tanto para a aprendizagem, como para o contexto educacional.

\section{Método}

\section{Participantes}

Participaram do estudo professoras que tinham na sala de aula crianças vítimas de violência doméstica e as diretoras das respectivas escolas, perfazendo um total de 18 professoras e 10 diretoras de escola, da cidade de Catanduva - SP e região. Dentre as professoras, nove trabalhavam em Escolas Municipais e nove em escolas da Rede Estadual. Quanto às diretoras, seis exerciam suas funções em estabelecimentos de ensino da Rede Estadual e quatro em Escolas Municipais.

\section{Materiais e Instrumentos}

A coleta de dados com as educadoras aconteceu nas dependências da escola. As professoras foram entrevistadas nas respectivas salas de aula; as diretoras em suas salas.

Para a coleta de dados foi utilizada uma Entrevista Semi-Estruturada. Este instrumento foi elaborado pelo primeiro autor para ser respondido pelas participantes, com o objetivo de conhecer as suas concepções sobre violência doméstica e sobre o desempenho escolar da criança vítima do referido fenômeno, perguntando, por exemplo, o que elas entendiam por violência doméstica, como percebiam o rendimento escolar da criança vitimizada e se esta seria um(a) aluno(a) com necessidades especiais de ensino.

\section{Procedimento}

Preliminarmente, o pesquisador manteve contato com a direção de cada uma das escolas freqüentadas por crianças vítimas de violência doméstica 
encaminhadas ao Fórum Judicial da cidade de Catanduva - SP, visando à autorização para a realização da coleta de dados no local, com o objetivo de caracterizar seu desempenho escolar. Nessa oportunidade foi apresentada a proposta da pesquisa. Com exceção de uma diretora de escola particular, as demais (todas, escolas públicas) autorizaram a realização da coleta de dados nas dependências da escola, bem como colaboraram.

$\mathrm{Na}$ fase final da coleta de dados com as crianças, suas professoras e as diretoras das escolas foram convidadas a participar da pesquisa, respondendo à Entrevista. Todas as educadoras convidadas aceitaram participar da pesquisa e assinaram o Termo de Consentimento Livre e Esclarecido. Cumpre informar que o projeto da pesquisa foi aprovado pelo Comitê de Ética em Pesquisa da Universidade Federal de São Carlos.

As entrevistas foram agendadas segundo a conveniência das participantes. Cada entrevista teve duração média de trinta minutos. A proposta inicial envolvia gravar as entrevistas, mas em razão das primeiras participantes deste estudo não autorizarem tal modalidade de registro, optou-se pela anotação, por escrito, dos dados obtidos. Todas as entrevistas foram anotadas pelo primeiro autor.

\section{Resultados}

Os dados obtidos nas entrevistas foram agrupados em seis categorias, a saber: Concepções sobre violência doméstica; Casos de violência doméstica na escola: Modalidades, Meios de identificação, Atuação no caso; Procedimentos que a escola deveria adotar para atender a criança vítima de violência em casa; Opiniões sobre o desempenho escolar da criança vítima da violência doméstica; Considerações sobre crianças com necessidades especiais de ensino; Criança vitimizada encarada como "aluno com necessidade educacional especial".

Para a apresentação e análise dos dados, as informações obtidas nas entrevistas foram divididas em tópicos correspondentes a cada uma das categorias acima citadas.

\section{Concepções sobre violência doméstica}

As participantes iniciaram a entrevista respondendo a uma pergunta aberta sobre o que entendiam por violência doméstica. Suas concepções sobre este fenômeno foram divididas em: adequadas, inadequadas e não específicas ao tema proposto; levando em consideração a literatura sobre violência intrafamiliar revista na introdução. A maioria das respostas das participantes $(78,11 \%)$ foi adequada, a saber, nomeando modalidades de violência doméstica: física $(26,56 \%)$, psicológica $(17,19 \%)$, sexual $(3,12 \%)$ e negligência $(9,37 \%)$, e práticas abusivas: espancamento, cárcere privado, estupro e falta de cuidados, as quais foram agrupadas nas respectivas modalidades para os efeitos desta análise.

Quanto às respostas inadequadas (7,8\%), revelaram concepções imprecisas sobre a violência intrafamiliar: "falta de recursos materiais que gera brigas do casal" (1,56\%); "separação dos pais" $(1,56 \%)$; "falta de cultura" (1,56\%) e "vida difícil" $(1,56 \%)$.

As concepções não específicas ao tema em questão corresponderam a 14,06\% das respostas das participantes. Foi considerado como resposta não 
específica aquela que não identificasse a presença de violência doméstica, por exemplo, o consumo de álcool por parte dos pais, ainda que tal fator fosse de risco. É importante esclarecer que no contexto marcado pela violência intrafamiliar o uso de álcool pelo agressor é comum (Guille, 2004), mas a recíproca não é verdadeira, ou seja, nem sempre o consumo de bebida alcoólica pelos pais implica em violência dentro do lar, ou seja, o álcool não é uma condição necessária ou suficiente para a ocorrência da referida violência. Além da resposta "uso de álcool pelos pais" $(6,25 \%)$, as educadoras também disseram: "falta de respeito" (4,69\%); "colocar o filho para fazer o serviço de casa" $(1,56 \%)$; "pais que descontam seus problemas nos filhos" $(1,56 \%)$ e "sei pela TV (mídia) e vejo casos na escola" $(1,56 \%)$.

\section{Casos de violência doméstica na escola}

Ao serem perguntadas se tinham conhecimento de casos de alunos(as) vítimas de violência doméstica na sala de aula ou na escola, 21 participantes $(75 \%)$ responderam afirmativamente e sete $(25 \%)$ responderam que não.

\section{Modalidades}

Dentre as participantes que deram respostas afirmativas, a maioria indicou, de forma adequada, alguma modalidade de violência doméstica (física, psicológica, sexual e negligência).

A única exceção foi apresentada por uma participante que respondeu "separação dos pais", o que não é uma modalidade do fenômeno em questão. A Tabela 1 ilustra que a modalidade mais frequientemente apontada foi a violência física $(51,51 \%)$, seguida por negligência, violência sexual e violência conjugal, sendo a modalidade violência psicológica aquela com menor porcentagem de respostas.

\section{Meios de Identificação}

A Tabela 2 apresenta os meios pelos quais as educadoras identificaram os casos de violência doméstica na sua escola.

As participantes identificaram casos de violência doméstica, na sua sala de aula ou na escola, por meio da criança: verbalização $(48,65 \%)$; marcas de ferimentos no corpo $(18,92 \%)$; comportamento $(8,11 \%)$ e por presenciar a criança sendo agredida na porta da escola pela mãe $(2,70 \%)$. Assim, um número expressivo de respostas das educadoras $(75,68 \%)$, apontou a própria criança como meio de identificação da violência intrafamiliar.

As demais respostas $(24,31 \%)$ indicaram que as educadoras souberam dos casos de violência doméstica por outras vias que não a própria criança, a saber: pelos familiares desta, por terceiros, por vizinhos e por funcionários da escola.

\section{Atuação no caso}

Considerando que $75 \%$ das educadoras disseram ter conhecimento da existência de crianças vitimizadas na escola, foi perguntado para as participantes que providências tomaram em relação aos casos de violência doméstica identificados no contexto escolar. As respostas a essa pergunta foram classificadas em adequadas e inadequadas, sendo que, praticamente, a porcentagem de ambas se equivale, respectivamente, $56 \%$ e $44 \%$. Dentre as respostas adequadas, $43,75 \%$ das participantes disseram que encaminharam os casos ao Conselho 
Tabela 1. Modalidades de violência doméstica constatada $(n=33)$.

\begin{tabular}{lcc}
\hline Modalidades & Freqüência & Porcentagem \\
\hline Violência Física & 17 & 51,51 \\
Negligência & 5 & 15,15 \\
Violência Psicológica & 3 & 9,09 \\
Violência Sexual & 4 & 12,12 \\
Violência Conjugal & 4 & 12,12 \\
\hline Total & 33 & 100,00 \\
\hline
\end{tabular}

Tabela 2. Meios de identificação dos casos de violência doméstica na escola $(n=37)$.

\begin{tabular}{lcc}
\hline Meios de identificação & Freqüência & Porcentagem \\
\hline A criança contou & 18 & 48,65 \\
Marcas no corpo da criança & 7 & 18,92 \\
A família contou & 4 & 10,81 \\
Comportamento da criança & 3 & 8,11 \\
Comentário de terceiros & 2 & 5,40 \\
Comentário de vizinhos & 1 & 2,70 \\
A participante presenciou & 1 & 2,70 \\
Por funcionários da escola & 1 & 2,70 \\
\hline Total & 37 & 100,00 \\
\hline
\end{tabular}

Tutelar. Outras atuações adequadas foram: encaminhamento para psicoterapia $(3,12 \%)$, encaminhamento para a psicóloga da escola (3,12\%); encaminhamento para a Delegacia de Polícia $(3,12 \%)$ e observar o aluno $(3,12 \%)$.

Dentre as respostas inadequadas, $12,5 \%$ das educadoras disseram ter conversado com a família; $9,37 \%$ conversaram com a criança; $6,25 \%$ conversaram com a mãe; $6,25 \%$ orientaram os pais; $3,12 \%$ ofereceram atendimento diferenciado para a criança; $3,12 \%$ trataram a criança com carinho e $3,12 \%$ ofereceram para a criança consolo e esperança.
Essas respostas foram classificadas como inadequadas porque não compete às educadoras manter conversa com a família e/ou com a criança para investigar o caso e, tampouco, orientá-las, sendo que tal intervenção, sem o devido preparo, pode ser ainda mais danosa para a vítima. É provável que ao dizer que fizeram ou que fariam alguma intervenção com a criança vitimizada, como atendimento diferenciado (carinho, consolo e esperança), as participantes tenham pretendido dar respostas socialmente aceitáveis (Brino \& Williams, 2003a). 
Procedimentos que a escola deveria adotar para atender a criança vítimizada

Após responderem o que fizeram, concretamente, enquanto atuação, nos casos de violência doméstica constatados na escola, as educadoras foram perguntadas sobre $o$ que poderiam fazer para atender a criança que sofre violência em casa.

A Tabela 3 mostra os procedimentos que a escola poderia adotar para o atendimento das crianças vítimas de violência doméstica, de acordo com as informações das participantes. Quando perguntadas sobre o que a escola poderia fazer para atender uma criança vitimizada, $28 \%$ das respostas obtidas foram: "oferecer um atendimento especial". Esta resposta majoritária foi seguida por: "comunicar o caso ao Conselho Tutelar" (18\%). A terceira resposta mais freqüente (16\%), foi: "encaminhar a criança para psicoterapia".

\section{Opiniões sobre o desempenho escolar da criança que sofre violência doméstica}

No que se refere ao desempenho escolar da criança vitimizada, a grande maioria das educadoras respondeu que tal desempenho fica prejudicado, correspondendo a $91 \%$ das respostas. Dentre estas, $44,12 \%$ disseram, taxativamente, que o desempenho escolar da criança vítima de violência doméstica fica prejudicado e 46,88\% ofereceram outros dados para nomear o referido comprometimento, como: "a família não se interessa pela vida escolar do aluno" $(11,76 \%)$; "perda de interesse" (8,82\%); "afeta a aprendizagem" (8,82\%); "baixo rendimento escolar" (8,82\%); "há comprometimento total" (2,94\%); "é ruim" $(2,94 \%)$ e "não vai bem, na escola" $(2,94 \%)$.
Cumpre esclarecer ainda que, para duas educadoras $(5,88 \%)$ a violência em casa não prejudica, necessariamente, o desempenho escolar da criança, pois para aquelas vai depender de cada caso. Uma participante (2,94\%), disse, categoricamente, que a criança vítima de violência doméstica não fica com o desempenho escolar prejudicado.

Ao responder se a violência doméstica poderia ou não prejudicar o desempenho escolar da criança, uma participante disse que vai depender de cada caso, mencionando, em seguida, sua experiência pessoal. Comentou que ela e suas irmãs foram expostas à violência conjugal, descrevendo um pai extremamente agressivo para com a esposa.

A educadora em questão concluiu seu relato afirmando que, apesar de ter sido vítima da violência intrafamiliar, tanto ela, como suas irmãs sempre tiveram um bom rendimento escolar e fizeram curso superior. Entretanto, ela acreditava que $o$ aspecto emocional sempre ficava comprometido.

\section{Considerações sobre crianças com necessidades especiais de ensino}

Em suas considerações, as participantes expressaram seus pensamentos sobre o que caracterizaria a criança com necessidades educacionais especiais. Tais informações estão contidas na Tabela 4.

A concepção majoritária $(50 \%$ das respostas obtidas para essa pergunta) foi a de que a criança com necessidades especiais de ensino (NEE) era aquela "com dificuldade de aprendizagem". Uma participante $(2,94 \%$ das respostas) disse que, para ela, a criança com "NEE" era a que tinha "distúrbio 
Tabela 3. Procedimentos que a escola poderia adotar $(n=50)$.

\begin{tabular}{lcc}
\hline Procedimentos & Freqüência & Porcentagem \\
\hline Oferecer um atendimento especial para a criança & 14 & 28 \\
Comunicar o caso ao Conselho Tutelar & 9 & 18 \\
Encaminhar a criança para psicoterapia & 8 & 16 \\
Dar orientação aos pais & 6 & 12 \\
Conversando com a criança & 4 & 8 \\
Dar para a criança amor, atenção e carinho & 3 & 6 \\
Comunicar as autoridades & 1 & 2 \\
Fazer reuniões com pais & 1 & 2 \\
Dar orientação às mães & 1 & 2 \\
Encaminhar ao médico & 1 & 2 \\
Comunicar a delegacia & 1 & 2 \\
Contar com profissionais especializados na & 1 & 2 \\
escola & 50 & 100 \\
\hline Total & &
\end{tabular}

Tabela 4. Concepções sobre crianças com necessidades especiais de ensino $(n=34)$.

\begin{tabular}{lcc}
\hline Concepções & Freqüência & Porcentagem \\
\hline Com dificuldade de aprendizagem & 17 & 50,00 \\
Com alguma deficiência & 4 & 11,76 \\
Com qualquer deficiência & 3 & 8,82 \\
Com problema neurológico & 2 & 5,88 \\
Com deficiência física & 2 & 5,88 \\
Com deficiência mental & 1 & 2,94 \\
Com comportamento inadequado & 1 & 2,94 \\
Que exige muito do professor & 1 & 2,94 \\
Com distúrbio de aprendizagem & 1 & 2,94 \\
Que precisa de atenção & 1 & 2,94 \\
Com dificuldade acentuada de aprendizagem & 1 & 2,94 \\
\hline Total & 34 & 100,00 \\
\hline
\end{tabular}

de aprendizagem" e uma outra educadora $(2,94 \%$ das respostas) falou em "dificuldade acentuada de aprendizagem". Portanto, 55,88\% das respostas apontaram para a questão dos problemas de aprendizagem. Com relação às opiniões das participantes sobre crianças com "NEE", a segunda resposta mais comum foi "criança portadora de deficiência" (29,4\%), sendo que nesta categoria estão incluídas as seguintes concepções: “com alguma deficiência" (11,76\%); “com qualquer 
deficiência"(8,82\%); "deficiência física" $(5,88 \%)$ e "deficiência mental" (2,94\%). Outras opiniões: "problema neurológico"; "comportamento inadequado"; "que exige muito do professor" e "que precisa de atenção", também foram mencionadas.

\section{Criança vitimizada encarada como aluno com}

\section{"necessidade educacional especial"}

Foi solicitado às participantes que informassem se para elas a criança vítima de violência doméstica poderia ser considerada um aluno com necessidades educacionais especiais. As respostas foram: depende (39,3\%), $\operatorname{sim}(35,7 \%)$ e não (25\%).

As educadoras ao responderem "depende", fizeram os seguintes comentários: "dependia do tipo de violência"; "dependia da intensidade da violência"; "dependia da faixa etária e do desenvolvimento da criança" e "que cada caso era um caso".

\section{Discussão}

Os dados obtidos com a pesquisa realizada revelaram as opiniões das educadoras sobre violência doméstica e desempenho escolar da criança vítima deste fenômeno.

Com relação à violência doméstica, as informações das participantes indicaram que possuíam um conhecimento superficial, de acordo com a literatura (Azevedo \& Guerra, 1989), mas coerente. Ao apresentarem suas opiniões, ou seja, o que entendiam sobre o referido fenômeno, as educadoras nomearam modalidades de violência que podem ocorrer dentro do lar e/ou deram exemplos de práticas abusivas. As respostas ainda revelaram preconceito por parte de algumas das participantes, bem como falta de conhecimento a respeito da violência doméstica.

Dentre as respostas consideradas inadequadas por não estarem em consonância com a literatura científica sobre violência doméstica duas, além de incorretas, revelaram idéias preconcebidas das participantes, como: "falta de cultura" e "separação dos pais". Quanto à primeira, cabe dizer que a violência intrafamiliar pode acontecer em qualquer lar, independentemente de cultura e do nível sócioeconômico (Azevedo \& Guerra, 1989; Saffioti, 1997). Mas, não só, essa educadora ainda apresentou uma concepção de senso comum sobre cultura. Em relação à segunda resposta, "separação dos pais", a literatura aponta que, em muitos casos, essa é a solução mais indicada, às vezes, até mesmo para pôr fim a violência dentro de casa (Fincham, 1998).

Mesmo com um discurso vago e até superficial, ao comentarem as experiências com alunos vítimas de violência doméstica, as educadoras revelaram um dado positivo, pois sabiam identificar a criança vitimizada, tanto pelas marcas de ferimento no corpo, como por meio do comportamento (perda de interesse, apatia, etc.). Essas informações revelaram que as participantes estão atentas à questão da violência em casa. Observar o aluno e reconhecer nela marcas de ferimentos que podem sugerir violência intrafamiliar foi um dado significativo, pois está de acordo com as recomendações do Estatuto da Criança e do Adolescente (Brasil, 1990).

Segundo as participantes, muitas crianças verbalizam seu drama familiar. Este dado sugere 
que a criança sente-se segura e protegida na escola, conseguindo quebrar o "pacto de silêncio" que a violência doméstica impõe às suas vítimas. Adicionalmente, tais resultados reforçam a importância da escola enquanto agente comunitário, não só denunciando os casos de violência intrafamiliar, como também desenvolvendo programas de prevenção com a população que atende (Hernandez-La Cruz, 1999).

As educadoras demonstraram habilidade para identificar a criança vítima de violência doméstica e foram capazes de nomear fatores de risco aos quais muitos de seus alunos, além das crianças participantes do estudo, estavam expostos nos seus lares, apesar do conhecimento superficial que revelaram sobre a violência intrafamiliar. Com a capacitação dos professores e diretores de escola (Brino \& Williams, 2003b; 2006) e com programas de prevenção (Hernandez-La Cruz, 1999), tais fatores de risco poderiam ser detectados e trabalhados precocemente, minimizando ou evitando seqüelas no desenvolvimento das crianças vitimizadas, bem como se evitaria que essas condições adversas caminhassem para a violência doméstica propriamente dita.

A atuação da escola nos casos de violência doméstica, identificados ou não pelas participantes, revelou atitudes contraditórias, em especial, quanto aos procedimentos a serem adotados, pois em associação com a resposta "encaminhamento do caso para o Conselho Tutelar", como recomenda o Estatuto da Criança e do Adolescente (Brasil, 1990), as educadoras mencionaram, na sua maioria, "oferecer atendimento especial para a criança", no entanto, as mesmas não estão preparadas para realizar tal intervenção.
Conduzir trabalho com as crianças (por exemplo, atendimento especial) e com a família (orientação), como indicado pelas participantes é preocupante, pois além de não terem, como ficou demonstrado, conhecimento suficiente sobre violência doméstica, a orientação para a família e, conseqüentemente, para o agressor, pode aumentar a possibilidade de revitimização da criança por conta do sentimento de retaliação do agressor (Brino \& Williams, 2003b).

O Estatuto da Criança e do Adolescente - ECA (Brasil, 1990) preconiza que os educadores devem comunicar às autoridades os casos de violência doméstica dos quais tenham conhecimento, ainda assim, o referido procedimento ficou em segundo lugar dentre as respostas apresentadas pelas participantes. A resposta mais freqüente envolveu dar para a criança, na escola, atendimento especial.

Vale dizer que, oferecer atendimento especial para a criança, como informado pelas participantes, além das respostas: "dar orientação aos pais"; "conversar com a criança"; "dar para a criança amor, atenção e carinho"; "fazer reuniões com pais" e "dar orientação para as mães" são procedimentos inadequados, pois os educadores não estão capacitados para fazer intervenção com a criança, menos ainda com a família. Portanto, essas atuações não são indicadas pela literatura e, tampouco, pelo Estatuto da Criança e do Adolescente (Brasil, 1990). Tais respostas sugerem que as participantes conhecem pouco ou não aplicam a legislação (Brino \& Williams, 2003a), sugerem ainda que não estão capacitadas para atender a criança vítima de violência doméstica.

A intervenção (conversa, orientação) das participantes com os pais, com a mãe ou com a 
família, é preocupante, pois as mesmas não possuem preparo para fazer essa abordagem. Tal procedimento, especialmente, quando a própria criança verbalizou sua condição de vítima, aumenta a possibilidade de ser novamente maltratada (Brino \& Williams, 2003b). A escola pode e deve ser um espaço para desenvolver programas de prevenção do risco psicossocial, como os oriundos da violência doméstica, mas, para tanto, é essencial a capacitação dos educadores (Hernandez-La Cruz, 1999).

Em relação ao desempenho escolar da criança vítima de violência doméstica, as participantes deram suas opiniões pautadas em sua práxis. Para a grande maioria delas o desempenho escolar da criança fica prejudicado. Além deste comprometimento, as educadoras mencionaram sequielas que observavam no comportamento da criança vitimizada, principalmente, a agressividade e a indisciplina apresentadas na escola.

Mesmo com essa opinião majoritária das professoras e das diretoras de escola sobre o desempenho escolar da criança vítima de violência doméstica, ao responderam se esta criança poderia ser considerada como aluno(a) com necessidades educacionais especiais (NEE), as participantes mostraram-se divididas entre três categorias de respostas, assim classificadas: "depende", "sim” e “não”.

Embora com opiniões pautadas unicamente na própria experiência profissional, as considerações feitas pelas participantes são pertinentes aos dados fornecidos pela literatura científica, em especial, a internacional, na qual há consenso em dizer que a criança vítima direta de violência doméstica apresenta declínio no desempenho escolar (Leiter \& Johnsen, 1997; Veltman \& Browne, 2001).

Ao apresentarem as suas concepções sobre crianças com necessidades especiais de ensino, as educadoras mencionaram as dificuldades de aprendizagem e os distúrbios de aprendizagem, evidenciando que estes últimos se devem aos fatores orgânicos. Del Prette e Del Prette (2003) relaciona os fatores orgânicos aos distúrbios de aprendizagem e os fatores socioemocionais às dificuldades de aprendizagem.

É sabido que conceituar e diferenciar, do ponto de vista teórico, os problemas de aprendizagem em distúrbios ou em dificuldades é polêmico, pois ainda não há consenso entre os autores quanto à sua origem (Almeida e cols., 1995). Segundo tais autoras, as dificuldades de aprendizagem não podem ser entendidas como sinônimo de distúrbios de aprendizagem, pois aquelas não têm origem apenas nas características pessoais do aluno, mas também nas suas múltiplas relações e interações com: a família, a escola, os professores, etc. Já estes, por sua vez, se devem, tal como defendido por Del Prette e Del Prette (2003) ás causas orgânicas (ao biológico). Em contrapartida, Moysés e Collares (1992) entendem que o termo dificuldades de aprendizagem se refere ao mesmo conceito de distúrbios de aprendizagem.

Cabe acrescentar que, seja empregando o termo dificuldades de aprendizagem ou utilizando-se a expressão distúrbios de aprendizagem, os educadores devem analisar o fracasso ou o sucesso escolar do aluno, considerando além das características pessoais deste, os seguintes fatores: família, escola e meio social, bem como suas interações. 
No caso da criança vítima de violência doméstica, o baixo rendimento escolar pode ser caracterizado como a presença de dificuldades de aprendizagem. Assim, seu desempenho acadêmico deve ser analisado levando-se em consideração não apenas as dificuldades individuais, mas também a interação entre suas características pessoais e os fatores relacionados ao núcleo familiar, à escola e ao meio social (Marturano, 1999).

Por fim, o estudo revelou que as educadoras carecem de esclarecimentos sobre o tema violência doméstica, bem como a respeito do Estatuto da Criança e do Adolescente (Brasil, 1990). Também, precisam conhecer a terminologia "necessidades educacionais especiais", pois demonstraram pouca ou nenhuma familiaridade com tal expressão.

Todas as educadoras convidadas a participar deste estudo, aceitaram o convite, no entanto, a maioria revelou muita preocupação em discursar sobre o tema, tanto que algumas não permitiram que a entrevista fosse gravada. É oportuno informar que parte da coleta de dados ocorreu em período de eleição, inclusive, para prefeito, assim, as participantes, em especial, aquelas que trabalhavam na rede municipal de ensino, verbalizaram sua preocupação em falar, justificando tal temor por conta da campanha política dos candidatos à prefeitura. Além de o temor político ser preocupante em uma sociedade democrática, ele também revela o quanto o assunto violência doméstica ainda é considerado um tabu por muitos.

Uma limitação desta pesquisa se refere ao número reduzido de participantes, principalmente de diretores de escola. Assim, seria interessante, no futuro, reaplicar o estudo com um número mais abrangente de participantes. É fundamental a produção de mais estudos que mostrem os reflexos da violência doméstica no rendimento escolar da criança vitimizada (Assis, 2002), não só em razão da complexidade de tal fenômeno, mas para se compreender a concepção dos educadores sobre o tema em pauta e assim pensar a escola não apenas como local de aprendizagem, mas também de socialização (Lisboa \& Koller, 2004), reconhecendo seu papel de agente comunitário, detectando fatores de risco na população que atende e desenvolvendo programas de prevenção (Hernandez-La Cruz, 1999).

\section{Referências}

Almeida, S. F. C., Rabelo, L. M., Cabral, V. S., Moura, E. R. O., Barreto, M. S. F., \& Barbosa, H. (1995). Concepções e práticas de psicólogos escolares acerca das dificuldades de aprendizagem. Psicologia: Teoria e Pesquisa, 11(2), 117-134.

Assis, S. G. (2002). Crescendo em Meio à Violência. Em M. F. Westphal (Org.), Violência e Criança (p. 115-124). São Paulo: EdUSP.

Azevedo, M. A., \& Guerra, V. N. A. (Orgs.). (1989). Crianças Vitimizadas: A síndrome do pequeno poder. São Paulo: Iglu.

Brancalhone, P. G., Fogo, J. C., \& Williams, L. C. A. (2004). Crianças expostas à violência conjugal: Avaliação do desempenho acadêmico. Psicologia: Teoria e Pesquisa, 20(2), 113-117.

Brasil (1990). Estatuto da Criança e do Adolescente. Juiz de Fora: Universidade Federal de Juiz de Fora. 
Brino, R. F., \& Williams, L. C. A. (2003a). Concepções da professora acerca do abuso sexual infantil. Cadernos de Pesquisa, 119, 113-128.

Brino, R. F., \& Williams, L. C. A. (2003b). Capacitação do educador acerca do abuso sexual infantil. Interação em Psicologia, 7(2), 1-10.

Brino, R. F., \& Williams, L. C. A. (2006). Brazilian teachers as agents to prevent child sexual abuse: An intervention assessment. Em D. Daro (2006). World Perspectives on Child Abuse ( $7^{\mathrm{a}}$ ed., pp. 75-78). Chicago: ISPCAN - International Society for Prevention of Child Abuse and Neglect.

Del Prette, Z. A. P., \& Del Prette, A. (2003). Habilidades sociais e educação: Pesquisa e atuação em psicologia escolar / educacional. Em Z. A. P. Del Prette (Org.), Psicologia Escolar e Educacional (p. 113-141). Campinas: Alínea.

DuPaul, G. J., Rapport, M. D., \& Perriello, L. M. (1991). Teacher ratings of academic skills: The development of the Academic Performance Rating Scale. School Psychology Review, 20(2), 284-300.

Fincham, F. D. (1998). Child Development and Marital Relations. Child Development, 69(2), 543-574.

Guille, L. (2004). Men who batter and their children: An integrated review. Aggression and Violent Behavior, 9(2), 129-163.

Hernandez-La Cruz, M. C. (1999). Prevenção de risco psicossocial na escola. Dissertação de Mestrado, Pontifícia Universidade Católica de Campinas, Campinas, São Paulo.

Leiter, J., \& Johnsen, M. C. (1997). Child maltreatment and school performance declines: An event-history analysis. American Educational Research Journal, 34(3) 563-589.
Lisboa, G., \& Koller, S. H. (2004). Interações na escola e processos de aprendizagem: Fatores de risco e proteção. Em E. Boruchovitch \& A. Bzuneck (Orgs.), Aprendizagem: Processos psicológicos e o contexto social na escola (pp. 201-224). Petrópolis: Vozes.

Marturano, E. M. (1999). Recursos no ambiente familiar e dificuldades de aprendizagem na escola. Psicologia: Teoria e Pesquisa, 15(2), 135-142.

Moysés, M. A. A., \& Collares, C. A. L. (1992). A história não contada dos distúrbios de aprendizagem. Caderno CEDES, 28, 31-48.

Pamplim, R. C. O. (2005). A interface família-escola na inclusão de crianças com necessidades educacionais especiais: Uma perspectiva ecológica. Dissertação de Mestrado, Universidade Federal de São Carlos, São Carlos, São Paulo.

Pereira, P. C., \& Williams, L. C. A. (2008). Desempenho escolar da criança vítima de violência doméstica encaminhada ao Fórum. Manuscrito submetido para publicação.

Rosemberg, L. (1981). Educação e desigualdade social: Rendimento escolar de alunos de diferentes origens sociais. Dissertação de Mestrado, Pontifícia Universidade Católica de São Paulo, São Paulo, São Paulo.

Saffioti, H. I. B. (1997). Violência doméstica ou a lógica do galinheiro. Em M. Kupstas(Org.), Violência em debate (pp. 39-57). São Paulo: Moderna.

Santos, P. L. (2002). Riscos, recursos e fatores de proteção associados ao baixo e alto rendimento acadêmico: Um estudo comparativo. Tese de Doutorado, Universidade de São Paulo, Ribeirão Preto, São Paulo.

Santos, P. L., \& Graminha, S. S. V. (2005). Estudo comparativo das características do ambiente familiar de 
crianças com alto e baixo rendimento escolar. Cadernos de Psicologia e Educação (Padéia), 15(31), 217-226.

Stein, L. M. (1994). TDE: Teste de desempenho escolar: Manual para aplicação e interpretação. São Paulo: Casa do Psicólogo.

Veltman, M. W. M., \& Browen, K. D. (2001). Three decades of child maltreatment research: Implications for the school years. Trauma, Violence, \& Abuse, 2(3), 215239.
Weinstein, R. S. (2002). Overcoming inequality in schooling: A call to action for community psychology. American Journal of Community Psychology, 30(1), 2142.

Wolfe, D. A., Crooks, C. V., Lee, V., McIntyre-Smith, A., \& Jaffe, P.G. (2003). The effects of children's exposure to domestic violence: A meta-analysis and critique. Clinical Child and Family Psychology Review, 6(3), 171-187.

Recebido em: 12/03/2007

Revisado em: 25/01/2008

Aprovado em: 05/06/2008

Sobre os autores:

Paulo Celso Pereira (paulocelsop@ig.com.br) - Programa de Pós-Graduação em Educação Especial - Laboratório de Análise e Prevenção da Violência Universidade Federal de São Carlos

Lúcia Cavalcanti de Albuquerque Williams (williams@ power.ufscar.br) - Departamento de Psicologia - Laboratório de Análise e Prevenção da Violência - Universidade Federal de São Carlos

Nota dos autores: Este artigo é parte da Dissertação de Mestrado do primeiro autor. 